of a temporary submergence to spread out the debris with such uniformity. During the retreat of the waters, pluvial action might perliaps wash away the softened soil in the regular manner described. AlfRed R. WALLACE

\section{The Number of Species of Insects}

PROH. HUXLEX is very much within the mark when he estimates the species of insects at "about I00,000, if not more." Were $I$ to estimate the number of described species at 200,000, I believe the figures would also fall short of the truth, even allowing a liberal margin for synonyms. In one order alone (Coleoptera) it is estimated that 80,000 species have been described.

I could enlarge upon the bearing these figures have upon theories on the geographical distribution of animals, but content mysclf with the remark that the groups of insects selected by writers on the subject are those in which colour is most prominent and structure least differentiated.

Lewisham, Jannary $\mathbf{2} 2$

\section{R. McLachlan}

[WE sent the above to Prof. Huxley, who has appended the following note.- "It was not my object to give an accurate estimate of the total number of species of insects. Gerstaecker, in the new edition of Brom's 'Thier-reich,' gives 200,000 as the total number of species of Arthropoda; but I dare say that Mr. McLachlan has good grounds for the claim he puts in for insects alone.

$$
\text { "T. H. HUXLEY"-ED. } 1
$$

\section{Meteor}

PizECISELY at 6 P.M., on the Igth inst., I saw a splendid mcteor traverse the sky from a point about midway between Orion's belt and the Pleiades to a point directly under the moon, and about $10^{\circ}$ above the horizon. It was pure white and dazzling, lasted about five seconds, emitted no sparks, except at the moment of disappearance, and was about half the size of the moon at the time.

Bray, Co. Wicklow, January 2 I

Diurnal Barometric Range at Low and Figh Levels

YOUR notice under this head (vol. $x v$. p. 287 ) of my paper on the daily inequalities of the barometer at Mount Washington and Portland, Maine, has hit a blot of which I was tunconsciocis until now. Had I been more than a student writing one of his first essays in meteorology, I should probably, like yourself, have suspected something wrong in the Portiand curve. The morning maximum and the afternoon minimum, as you point ont, occur very much earlier than is usual.

Differences varying from $+0^{.027}$ inch to $-0^{\circ} 004$ inch between your averages of Creveral Myer's figures and those given in my paper did not surprise me, as mine were intended to represent the temperature of $60^{\circ} \mathrm{F}$., while you have probably taken the observations either as already reduced to $32^{\circ}$, or have yourself reduced them to this temperature. My own impression is and was that the printed observations are not corrected for temperature, and in order to make the comparison with as little change as possible in the original figures for the three stations I brought each to something near a mean temperature for the three attachcd thermometers. Unfortunately, and here comes the biot, I now find that, by some mischance, in taking out the differences for Portland the external temperatures were taken instead of those by the attached thermometer. I exceedingly regret this, and shall as early as practicable make the required correction.

Fortunately this error does not affect the purport of my paperor the suggestions which $I$ offer in it towards the explanation of the long-vexed question of the cause or causes of the daily inequality of the barometer.

An acquaintance with the variations of the daily barometric curves, which depend on change of season and difference of locality, would undoubtedly be of assistance in drawing these curves when the observations for only a few hours are given, but the six hours for which the Portland figures are given are so well distributed as to leave little uncertainty as to the general form of the curve in this case. I should not, however, be satisfied with any curve for the Portland observations which, when anaiysed by the usual formula and reconstructed from the co-efficients thus obtained, did not reproduce the original observations, and also the interpolated values for the other hours, within a limit of error of 0.001 inch. Unless your curve can stand this test I shall not be satisfied with your deductions as to the epochs of maximum and minimum values, Having had much experience in drawing such curves, $I$ venture to assert that the Portland observations, whether taken as they are printed or after a correction for temperature, will still give the morning maximum and afternoon minimum of the barometer much earlier than is usually the case in this country. If my paper draws attention to any singularity of this kind it will mitigate the disappointment caused by the mistake in the temperature correction.

I append the times of maxima and minima for Portland, May, $\mathbf{1 8 7 2}$, as corrected ; also similar data for five years at the Naval Observatory, Washington, U.S., and for Oxford, England.

Times of Daily Maxima and Minima of the Barometer for the Month of May.

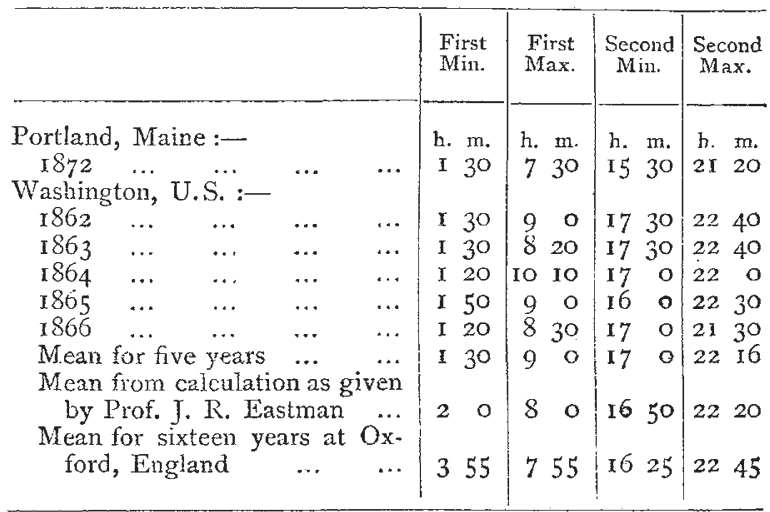

Liverpool, January 5

W. W. RUNDELL

\section{Former Climates}

IT appears to be estabiished that a climate favourable to the growth of coal plants and coral builders has prevailed in latitudes where the sun now shines for about seven months out of twelve.

Without inquiring how it came about that a warm sea once washed polar coasts, it would be interesting to learn whether the plants and animals concerned in the production of coal forests and coral reefs can flourish under these conditions of light supply.

Holmwood, Pufney Hill D. PIDGEON

\section{Tape-worms of Rabbits}

HAVING had occasion to dissect a number of wild rabbits, I have been surprised to find that the majority of them are infested with a large species of tape-worm. Can any of your readers inform me whether the life-history of this parasite has ever been made out? The case appears to be a remarkable one, because the host cannot here be suspected of ever taking animal food. Uniless, therefore, we suppose that the tape-worm of a rabbit differs from other tape-worms in not passing through a hydatid stage, it becomes difficult to explain the very general occurrence of this species.

George J. Romanes

\section{POLARISCOPE OBFECTS}

THE following is an interesting combination :--When the polariser and analyser are crossed, insert a concave plate of quart $z$ cut parallel to the axis, with its axis inclined at $45^{\circ}$ to that of the polariser, add to this a quartz wedge cut also parallel to the axis, having its axis placed perpendicular to that of the concave plate. The coloured circles, shown by the concave plate alone, will be seen to be displaced in the direction of the thicker edge, to a distance dependent upon the angle of the wedge. Also, as the wedge is made to slide in or out, the circles will be seen to expand or contract, according as the thicker or thinner part of it is presented to the field of view.

The explanation of this is to be found in the fact that a combination of two crystalline plates is optically equivalent to a single plate, whenever the axes of the plates are either parallel or perpendicular to one another. This follows immediately from a comparison of the mathematical expressions for the intensity of the light at any 